\title{
ONLINE NEWS AND PUBLIC SPHERE FOR COLLECTIVE SENSE-MAKING DURING BANGKOK RATCHAPRASONG BOMBING
}

\author{
Sakulsri Srisaracam
}

Faculty of Communication Arts, Panyapiwat Institute of Management, Thailand

\begin{abstract}
Immediately following the Bangkok Ratchaprasong Bombing incident in 2015, Twitter and web forum 'Pantip' became key avenues for the public to communicate and seek information to help make sense of a senseless situation. During critical periods of the crisis, media organizations' Twitter account and online news were the main sources of information. The purpose of this study is to understand the relationship between online news coverage and the public sphere in social media contributing to the collective "sense-making" during a violent crisis. This case study is based on content analysis of Twitter, web forum "Pantip" and five news websites nine days after the bomb blast at Ratchaprasong intersection. The results will demonstrate that online news and social media public sphere can play a vital role in collective "sense-making" during crises and the emotional pattern change is influenced by news coverage. Journalists play an important role as information seekers and fact distributor, while the online public sphere is used to gather information, discuss possible reasons behind the bomb attack, and crowdsource efforts to find the suspect. If news coverage can provide the necessary information, confusion and panic is likely to decrease. Thus, the study expands on the suggestion of the model of participatory process between collective online communities and journalists in times of crises to foster a more effective "sense-making" process.
\end{abstract}

Keywords: journalism; public sphere; social media; sense-making; crisis

\section{INTRODUCTION}

On the evening of August 17, 2015, a huge explosion went off around $7 \mathrm{pm}$ local time at the Erawan Hindu Shrine Ratchaprasong intersection - a popular shopping area in Thailand's capital Bangkok. The explosion caused many deaths and many more injuries. The incident happened during rush hour as many were getting home. It sent shockwaves through the community. This event saw a high level of social media activity - including online users breaking the story on Twitter, followed by journalists reporting on the scene and verifying information to confirm the incident. Then on August 18 came the second bomb. This time at Sathorn Pier, and again it caused panic and fear among people. During critical periods of violent crises, uncertainty and doubt can spread easily. Widespread adoption of social media has enable the public to react to violent crises as never before. During the 9-day-period studying the media response to the crisis, there were high levels of social media activity - including information seeking, information exchange, information verification, spread of rumors and misinformation, emotional response and crowd participation in identifying bombers. People reacted to the situation with panic, fear and sought information via social media while mainstream media tried to respond to the situation quickly to inform people what happened via online and social media to easily connect with the online community. Several studies have examined the dynamics of communication and public sphere during crises. Less understood is how social media mediate and amplify the 'sense-making' process, and media's role in guiding the society through the crises. This study relies on the qualitative method of content analysis to explore the relationship between social media tools, extraordinary events, the role of media and the 'sense-making' process. It analyses the content which online users communicated on Twitter

Corresponding Author: ajarnice@gmail.com 
and the popular web forum Pantip, as well as the media coverage through online news content and Twitter.

The following research question guided the study:

RQ1: What is the pattern of communication of media professionals and online users during violent crises?

RQ2: How do online news coverage and the public sphere in social media are contributing to the collective sense-making during a violent crisis.

\section{LITERATURE REVIEW}

\section{'Sense-making' during Crises}

'Sense-making' is a theory developed by Dervin (1983) that focuses on information seeking and sharing used in constructing one's world. Sensemaking has been studied in the context of communication, particularly during crises. Darvin and Frenette (2003) suggested that people use their emotions, past experiences, attitudes, feelings, and intuition to make sense of senseless situations. Sensemaking during crises, emergencies, and uncertain situations places greater strain on the process and people will need to interact and communicate more to gain enough information to understand what's happened and make it rational. The period when people feel the situation around them is uncertain and not rational is called 'critical period' (Weick, 1993). Similarly to what Shrivastava (1987) explained, the critical period of the crisis is when the crisis is unfolding and can last for minutes, hours or days. This period ends when the danger has been removed, people ease from uncertainty over the situation and the recovery period sets in. During this time, individuals try to bridge their cognitive gaps by looking for answers through all available channels. Thus, talking, interacting and holding a conversation with others are key elements of people's sensemaking process during crises (Muhren et al., 2008). Some research shows the pattern of behavior of people who try to make sense of crisis situations; some explain how media cover the story and give information to the public during times of crises. However, previous studied haven't shown the relationship between the public sphere and media's role during crises.

\section{Social media and communication during crises}

Communication and gaining the right information during crises can help individuals know how to react to the incident. Communication on social media among individuals played an important role in the responses, decision-making, and actions of those impacted by crises (Garnett and Kouzmin, 2007). Individuals communicate with each other to participate in crisis response and to meet the immediate needs of their communities, such as understanding the incident, alerting family and friends, and helping support rescue agencies to response to the emergency (Wachtendorf and Kendra, 2005). Although news-media organizations have played a vital role in disseminating official messages to the public since they are able to quickly reach a wide audience via social media and news website, individuals value also want additional information that is more specific to their needs and circumstances (Freimuth, 2006). Sometimes information from people on the scene, neighbors, family and other members of the community can satisfy information needs more than information given by officials. (Fessenden-Raden, Fitchen, and Heath, 1987). The use of social media makes communication easier, more immediate, as well as broader, connecting multiple networks of people at the same time. Individuals used microblogging websites such as Twitter for their own personal as well as collective sense-making called the process of 'talking cure' or voicing their feeling or inner thoughts until they find a sense of relief (Heverin, T., and Zach, L.,2011). Some studies suggested that during crises, information flow all over Twitter. Twitter provided its users with a shared platform to talk about the disaster. (Shaw F, Burgess J, Crawford K and Bruns A, 2013). Palen and Vieweg's (2008) research on university shootings uses textual analysis of online conversations after the 2007 Virginia Tech and the 2008 Northern Illinois University shootings. They found that people were engaging in practices of collective social creativity to deal with the crisis (Palen and Vieweg 2008). The use of Twitter during disaster events supports backchannel communication to find the information to deal with disaster situation, although spread of misinformation is also a concern (J. N. Sutton, 2010). In violent situation study, collective communication via social media can unite community spirit and guide people through upsetting 
events, such as the 2005 London bombings. (Drury,Cocking, and Reicher, 2009). Users turn to these platforms to participate in a wide range of information activities, e.g. to share information (Starbird et al., 2010). Other research has investigated collaboration among individuals to negotiate and solve an information problem, as was the case in identifying the names of the victims of the 2007 Virginia Tech shooting (Vieweg, Palen, Liu, Hughes, and Sutton, 2008). Public and official bodies participated in creating a mechanism for crowdsourced intelligence, which took the form of an automated tip-gathering service to identify violent suspect during the Boston marathon bombing. However, there is increasing concern over the spread of false information, - this is where traditional media could play an enormously valuable role by separating fact from fiction and providing verified, trustworthy information. (Tapia, A. H., LaLone, N., and Kim, H. W. 2014). The question for this study is how the use of social media can contribute to a collective understanding of violent incidents and roles of public sphere and media coverage during extraordinary events has yet to be addressed.

\section{RESEARCH METHODS}

The aim of this study was to investigate the pattern of communications during crisis and relationship between online news coverage and public sphere in social media contributing to collective sense-making during the critical period of violent crises. This study identified nine days of critical period of violent crisis in which members of the public turned to social media as a means of sharing information and reactions to the incident. Meanwhile, media covered the violent event and provided information during the crisis, which the public cited when they exchanged and sought information.

This study has two categories of samples - online user public sphere and media coverage. In order to analyze the relationship of communication of online users and the media during this crisis, this study collected data from three online platforms - Twitter, the web forum 'Pantip', and online news websites.

To study the online public sphere, this study collected data from two platforms - Twitter and web forum called Pantip, while collecting data of media coverage on Twitter and five news websites. Period of study is nine days from the evening of August 17, 2015 when bomb blast at Ratchaprasong intersection to August 25,2015 when the numbers of messages and news coverage found at lowest level.

Twitter allows users to send messages of 140 characters via web-based applications, cell phones, and various social media sites. Citizens turned to Twitter as an information sharing resource in searching for the suspect (Cook, 2009). In several crises, members of the public were using hastags to exchange information about the crisis as collective communication (Heverin and Zach, 2012). Hashtags are a user-driven method for categorizing tweets about specific topic, where collective communication occurs. Using the Twitter search API, I collected all publically available tweets based on the keywords related to 'Ratchaprasong Bomb' and also with the hastags related to incident. This study was able to observe a continuous stream of related messages. All tweets were collected and then categorized into public tweets and media tweets.

Web forum is a platform for group discussion. Pantip is the most popular web forum in Thailand where active citizens gather to exchange, verify information and discuss public issues. I collected data from the web forum by searching topics related to the keywords of "Ratchaprasong bomb".

Online news coverage data was collected from top five most popular news websites as listed by Thailand Web Directory and Advance Web Statistics, truehit.net, in August 2015. (Data provided the mostvisited news sites ranked by specific web addresses available at the time of sampling.) Top 5 news websites in this study are

- www.thairath.co.th/,

- www.dailynews.co.th/

- www..khaosod.co.th/

- www.matichon.co.th/

- www.manager.co.th/Home/

Data collected for this study were analyzed using content analysis and discourse analysis techniques to understand the pattern of communication being studied. The manual coding was developed to classify type of communication including storytelling, attribution, type of message, use of user-generated content, issues and topics and level of participation. 
Messages containing various types of content and issues were coded in multiple categories. Coding also identified three main categories of messages: information-related, opinion-related, and emotionalrelated. Topics, issues, and message categories are shown in time-series plots to analyze development of collective pattern of communication and inter-media agenda setting of online users and media news coverage during the crisis. This study also conducted discourse analysis of tweet, message on web forum, and online news coverage to identify pattern of sensemaking. I analyzed both the language used and how the message responded to sense-making process of information and emotion exchanging.

\section{RESULT}

\section{How do people communicate during crisis?}

Data collected from online user: 1105 original tweet (exclude retweet). Twitter is used for 'breaking news', 'information gathering and sharing'. Collective conversation occurs when using \#hashtag. Number of tweets and frequency of post was tense during August, 17-18 because people wanted information about the blast and crowdsourced to identify bomber. Number of tweets drop as time pass because people get enough information and information satisfied their need of 'sense-making' and made them feel secure, stable and more certain about the incident.

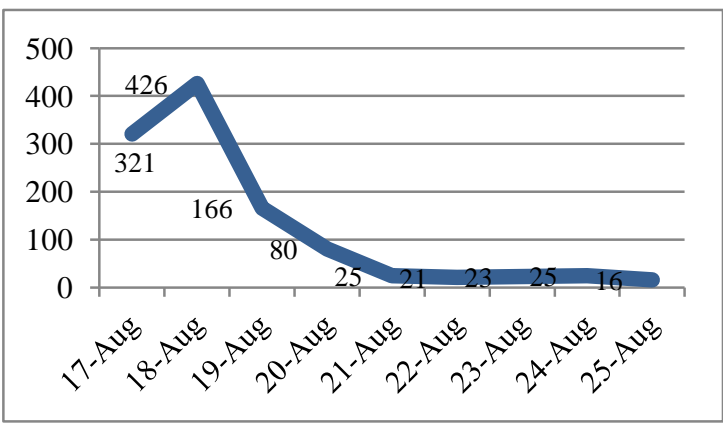

Figure 1 Time-series of number of online user tweets

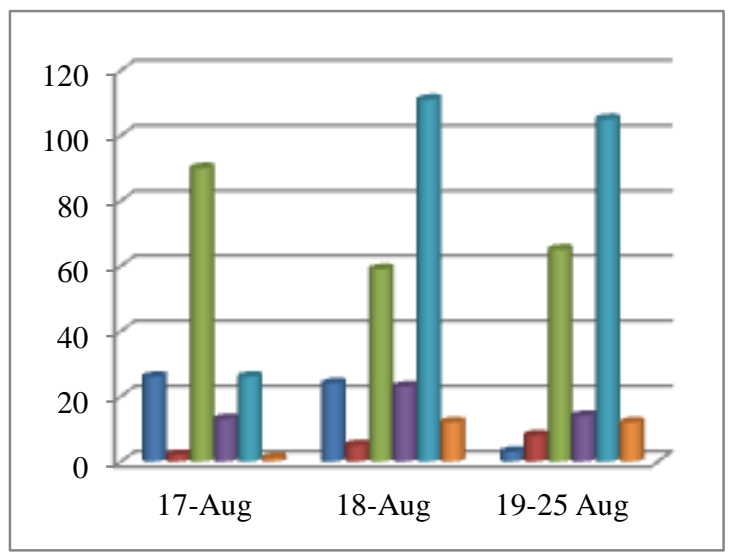

- Witness on scene Friends \& acquaintance - Media a Officials anfluencer

Figure 2 Attribution of information on Twitter

People communicated on twitter by using text the most, along with other content format such as pictures from the scene and links to information. On August 17, people communicate via text to seek, exchange information, and express feeling. During August 18-25, people communicate via many forms of content because there are more information, especially CCTV picture and VDO Clips. However, people still relied on sharing information form 'media organization'. Result also shows that during August, 17-18, number of user-generated content using was higher because people participated in indentifying bomber.

Half of tweets used 'attribution' from media coverage and online user-generated content (UGC). Witness on scene was cited the most on the first 2 days because people seek information to understand what had happened and how the situation in the area was. Data also shows that more than half of tweets were 'emotional expression' and 'information without source', which effect reliability of information. People tended to attribute media coverage when they want to share reliable and verified information. Meanwhile, citing online sources occurred when online content containing emotional or expression that full fill sense-making needs. This can imply that media role is trusted and verified source, while online discussion plays parts of crowdsourcing, mobilizing, exchanging belief and attitude toward incident. 


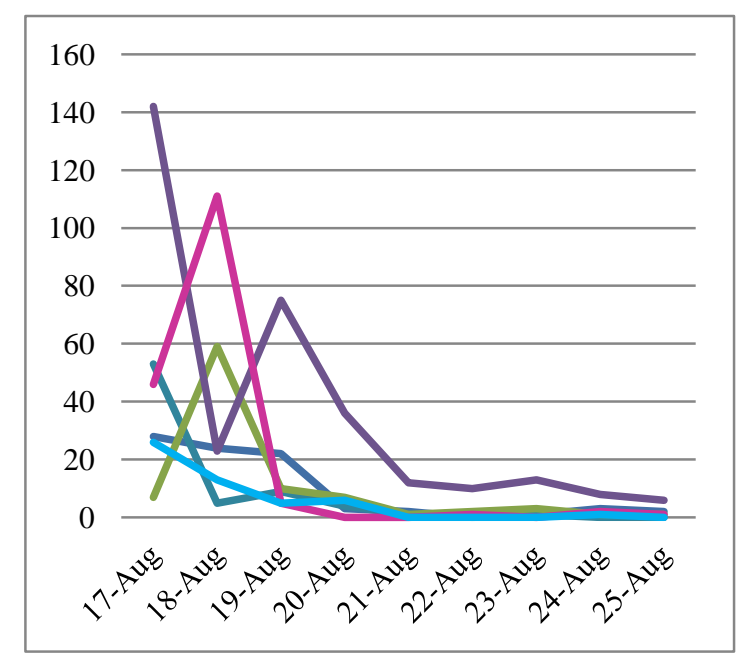

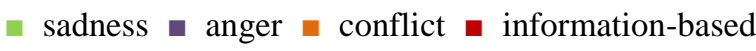
- fear and nervous c confusion

\section{Figure 3 tone of tweets people communicate}

Issue raised among online users depends on updated information and important evident. For example, CCTV released, officials discourse and unethical acts of media. Need of information was various from times, conversation focused on issues of 'incident' and 'identifying suspect'. There was confusion of information during crisis, rumors, and spread of fault data. Fact-based communication stayed throughout the period of study, people used it to gather and share information.

Meanwhile, people also expressed feeling toward incident. Fear and nervous expression was highest on the first day right after the incident, and at the same time of spreading confusing information. After gaining more information, fear and nerve of people gradually decreased. People also communicated with conflict and anger when trying to identify who was behind the incident and when tried to explain reason of the incident. Emotional-based communication also found when people feel unsure about situation.

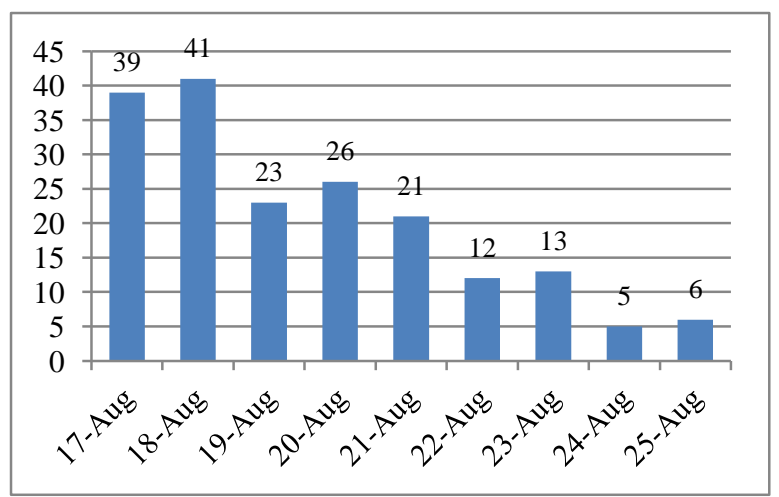

Figure 4 Number of topics on web forum Pantip

Pantip is web board platform that allow anyone to start a topic and anyone to respond to one so form of communication is more 'conversational' than Twitter. Online users discussed, debated, shared information and crowdsourced useful data under topics.

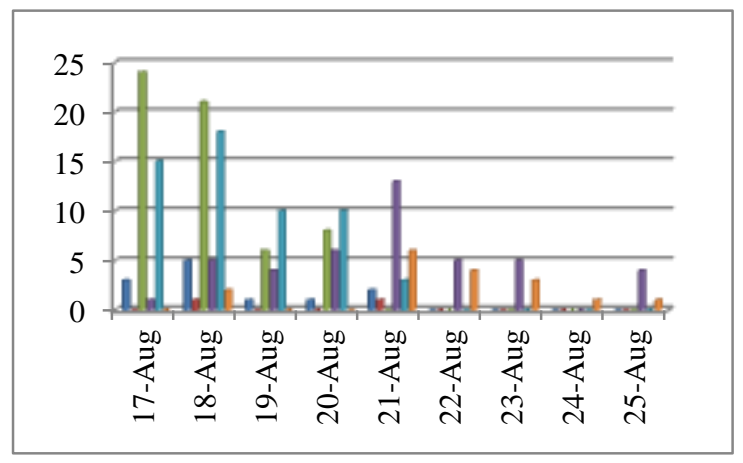

- Witness on scene Friends \& acquaintance - Media a Officials $\square$ Influencer

\section{Figure 5 Attribution of information on Pantip}

Topics are posted frequent on August 17-18, mainly focus on incident and crowdsource to identify bomber. During August 24-25, people get load of information about the suspects, the feeling was frustrated over officials' slow progress of investigation.

People cited from online sources and media because they need evident to support discussion about the incident. During August 17-20, attribution from media and online sources were used to follow updates. Officials were sourced about investigation process. On August 21-25, public stopped quoting media coverage because media had already given basic data. During this time active users on Pantip were debating and crowdsourcing online sources to explain situation. Online Influencers played important role, especially on critical conversation toward event. 


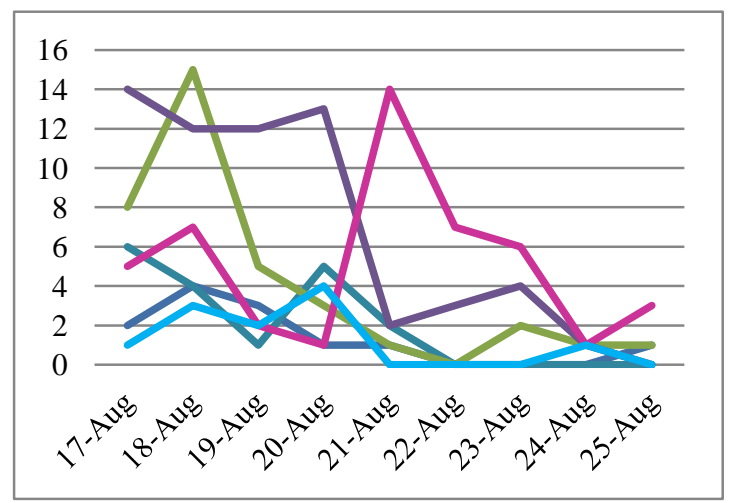

- sadness a anger a conflict a information-based n fear and nervous $=$ confusion

Figure 6 tone of tweets people communicate

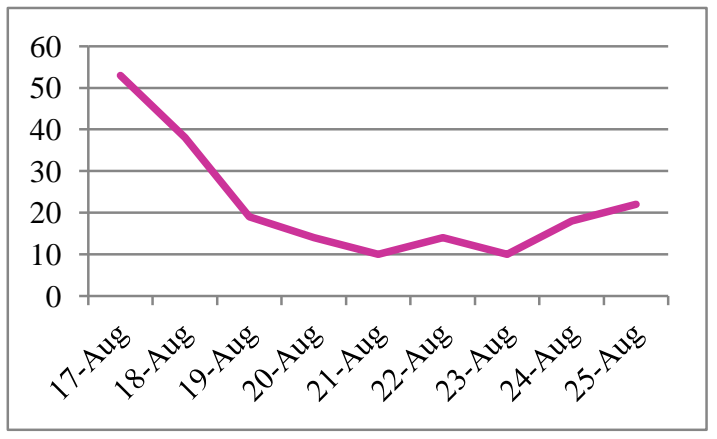

Figure 7 time-series of interaction on topics on Pantip

People also use web forum as an online public sphere to question about the incident; they tried to find cause and reason behind the incident by linking it to 'conflict issues', including national issue, political issue and international issue. Information is value during crisis and people need enough information to 'make-sense' of what happening. If information and expression from other individuals, media coverage and officials cannot bridge the gap to make situation rational, emotion expression such as fear and nervous rose. Discussion about cause of incident fuel 'anger and conflict' among online users. Level of participation and talks was higher when exchanging information. Pantip is all about discussion so there were both agree and disagree comments on each topics. Emotional interaction depended on information exchanging.

\section{News Coverage: how media report news during crisis?}

News coverage on Twitter focused on breaking stories, updating latest information and cross- promotion with hyperlinks to content on main platform of news-media organization.

Journalists use Twitter most during the night of breaking story. New-media Twitter accounts were for breaking news as it happened, verified information and cleared off rumors. Journalists and crowds on social media interacted on twitter to share usergenerated content related to incident, check information, and crowdsource evident to find suspects. However, use of 'Twitter mention' between journalists, media account and people on Twitter were only occurs when people ask for information.

Twitter is also used as 'cross-promotion platform'tweeting links to other information or in-depth news coverage from other platforms.

Thus, Twitter of media accounts responded to realtime sense-making, where speed and accuracy is essential. Media should establish role of curator to gather, verify, and report all information at the same place. Also, media and public should introduce common hashtags and join together to contribute useful information as collective communication during crisis.

Online news coverage was more about giving information and explain situation. Online news coverage provided short news, breaking news, singleangles story with one source. News Website role was 'information provider'. For In-depth and giving context in coverage, there are three categories of news.

First, opinion-based report to analysis data of event and explain situation, critical opinion towards officials action and media responsibility on reporting the news correctly and ethically.

Second, fact-based coverage to explain and give context. People use this information to explain why incident happened.

Third, emotional-based coverage is storytelling from 'people' point of view such as victim story, the way people continue their lives during crisis, and impact on people in general.

These three types of coverage can respond to sensemaking process by giving information and ease unwanted emotional expression toward incident. 


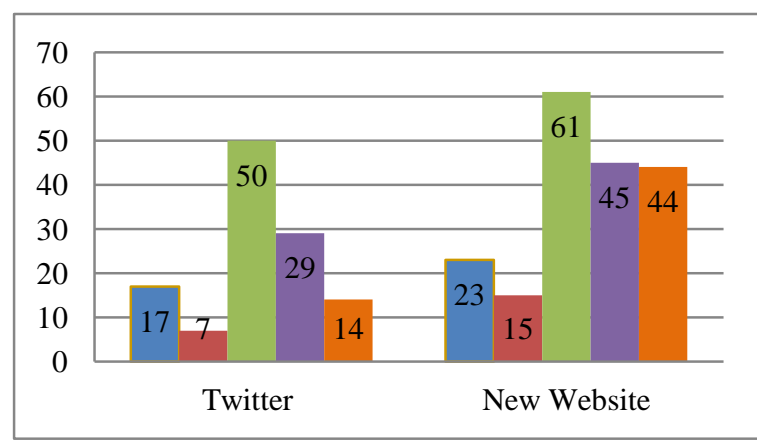

- Conflict Frame = Responsibility Frame - Human interest Frame $\backsim$ Morality Frame $\backsim$ Economic Frame

Figure 8

News-media organization also frames issues when covering crisis. Human interest was main communication frame, and main issues is about restore, reconstruct and rescue. Stories under this frame represented human touch and feeling from the people affected by the incident. Complain and critical opinion raised during August 23-25 because of slow process of investigation. News frame then shift to emphasis on 'Responsibility Frame', to push officials toward investigation and giving information to meet public needs. Meanwhile, economic frame concentrated on 'impact on tourism' and try to ensure investors about the situation.

\section{Sense-making during crisis}

I used discourse analysis to address research question of relationship between public sphere and media coverage contributing to collective sense-making during a crisis.

The study found that there were two communication types in the process of sense-making during violent crisis at Ratchaprasong intersection; informationbased collective communication and emotional-based expression.

Information-based content is highest on the first day after bomb had exploded. During the onset of the critical period, individuals tweeted to contribute information to collective conversation about the violent crisis. The sharing and verifying information was at high volume before officials and media stepped in to lead information sharing. During this time rumors and information, which could lead to misunderstanding of the incident also spread quickly all over Twitter, as well as, media cover it without verifying. Individuals sometimes contributed conflicting information to conversation by questioning the information, asking for clarification, or stating the correct information.

Then information-related content significantly dropped on the following day. Individuals posted information mainly from news-media reports. On this day people didn't exchange much information because there weren't any update information from officials. On August 19, CCTV of suspect picture was released and people started sharing and discussed to identify the suspect. On web forum Pantip, number of topics significantly increased and people crowdsourced information about bombers.

Then, information-related stay at steady level throughout period of study. In some cases, individuals posted questions to the collective conversation about the violent crises, trying to make sense of what happening. Individuals tried to examine reason of the incident and questioning outcome of the crisis affecting their lives and nations.

In contrast, emotional expression was low when people sharing information but when individual asking question, discussing and giving opinion about the crisis, emotional-based content rose. On August 18, emotion expression was at peak because the second bomb had exploded at Sathorn Pier, among uncertainty of situation; people expressed fears, anger, and worry on continuing their routine lives. Media also covered the incident with lots of unsure information, nervous and anger feeling towards the crisis also increased. During this timed people gathered information and rational explanation, but there was not yet enough information to satisfy the needs.

Emotional expression dropped and stayed steady when media stepped in to explain situation more clearly. However, from discourse analysis of news coverage, it's shown that 'quotes of high raking officials' that media used in coverage tended to be conflict discourse and some linked to political conflict in Thailand. When that kind of discourse appeared on media, anger and conflict conversation rose among online discussion too.

Thus, emotional-based content contributing to collective conversation were messages containing fears, anger, hope, unity and frustration. And it depends on what kind of information received. 
Throughout the critical period of the crisis, individual posted new information and, in some cases, provided sources of information to help each other in collective communication to understand what happened. Media played role of information provider and sometimes explainer to help making sense of the situation.

\section{DISCUSSION}

During nine days of crisis, media and journalist well respond to people's sense-making process in term of information sharing, information negotiating and information seeking. News website emphasized on identifying bomber, investigation process, incident information, rescue, restores and casualty. Online news has opinion pieces written by columnists and journalists to critic and analyze data of the incident, especially 'cause of incident'. Information-based coverage contributed to sense-making process by giving explanation to the incident. Emotional-based coverage reflects emotion, attitude of people toward incident. Sadness and feeling of lost encourage unity and patriotism action during crisis.

People using online public sphere - Twitter and web forum - to share information, seek information, give opinion, crowdsource evident, and express feeling.

Hashtag is needed for 'collective conversation' on Twitter. Forum like Pantip is about 'discussion, debate and crowdsource'.

Officials and media have to respond effectively to 'information need' of people during crisis. Verification is important to prevent unstable emotional in society. Twitter \#hashtag is necessary during crisis to monitoring data and emotion, crowdsourcing and verifying data. Meanwhile web forum is space for crowdsourcing activity.

The results of the analysis show that the nature of online public sphere communication changes over time during crisis. The time-series and discourse analysis of Twitter stream and Pantip topics shows that information sharing dominates collective communication while emotional expression substantially changes depending on information gained. This aligns with previous research of Garnett \& Kouzmin (2007) stating that during crisis, sharing and seeking information is essential activity.

Emotion expression of anger and conflict when trying to identify cause of incident, fueled by analysis and opinion type of news coverage can sometimes leads to hate speech discourse against different side of political supporters since political conflict is still linger among Thais. However, positive effect of individual emotional expression of people and emotional-based coverage is drive of national unity and mobilization of rescue and supports. This result agreed with previous study that the offering of opinions or personal views during crises play a role in sense-making, as more details emerged, uncertainty decreased and people can make sense of situation as well as participating in restoration and relief process. (Muhren et al., 2008, Dervin and Frenette, 2003)

People need information to make sense of the incident. Information influences tone of communication and society emotional action. As the result states that public usually cite information from media and online users when sharing information and discuss about incident, curator role is necessary role to gather information, verify, and confirm reliable data during crisis. Both media and online users can do this job, or do it together. However, media should learn about 'timing and silence' by monitoring public discussion and emotion to effectively respond to sense-making that can prevent unwanted action such as hate speech and anger.

Crowdsourcing is another activity found in this violent crisis study, online users actively participating in finding evident to identify bomb suspect. NewMedia should build 'community' and encourage participatory journalism.

However, there is concerned issue that crowdsourcing should not push official to release too much investigative details before the right timing. Crowdsource is necessary during crisis but newsmedia organization should verify, interact with sources, act as information gatekeeper and report to confirm fact and clear of rumors.

\section{CONCLUSION}

The results of this study contribute to our understanding of relationship between individuals' collective communication in social media and news coverage contributing to sense-making process in the context of violent crisis. Information behavior including sharing, seeking, negotiating and questioning of information between individuals and media shows that information is essential to ease 
uncertain, fears and anger emotional expression. Sadness and lost plays role in unite people in society and mobilize help and supports. However, amidst of early stage of violent crisis, news-media and officials should step in quickly to provide verify information to prevent chaos among public. On social media, there are rumors and misleading conversation that could raise conflict, thus, news coverage should explain the situation clearly and be aware of extreme opinion piece and conflict discourse from influencers.

Research also shows that networked of people on social media can work together to come to an understanding of situation as align with other previous research (Vieweg et al.,2008), in which stated that the connectivity of information flow in social media may be able to facilitate collective sense-making process. Thus, social media is becoming primary public sphere for informationsharing and crowdsourcing evident and could be vital for crisis response to engage people in shaping online conversation to make sense of senseless situation.

Meanwhile, news-media still has important role contributing to sense-making process during crisis by providing information and framing public emotional response toward crisis events. Media frame information in ways that help people positively confronted violent situation with explanation of the incident appears to help people understand the event and unit to recover spirit within society. During crisis, news-media should establish networked and has special team to monitor online discussion and emotion flow on social media to effectively cover stories with information people need to know. Role of new-media is information provider, explainer, curator and community conductor to participate and contribute to sense-making process. For further research is to understand more about the impact of real-time communication tools such as social media on collective sense-making. It could help newsmedia, public and official design pattern of communication during crisis more effectively.

\section{REFERENCES}

Cook, J., 2009, Washington Police Shootings: A Watershed Moment for Twitter?, Date of access: 21/03/2016. http://www.techflash.com/seattle/2009/11/

Fessenden-Raden, J., Fitchen, J.M., and Heath, J.S., 1987. Providing risk information in communities: Factors influencing what is heard and accepted. Science, Technology, \& Human Values, 12(3-4), 94-101.
Freimuth, V.S., 2006. Order out of chaos: The selforganization of communication following the anthrax attacks. Health Communication, 20(2), 141-148.

Garnett, J.L and Kouzmin, A., 2007. Communicating throughout Katrina: Competing and complementary conceptual lenses on crisis communication. Public Administration Review, 67, 171-188.

Heverin, T., and Zach, L., 2012. Use of Microblogging for Collective Sense-Making During Violent Crises: A Study of Three Campus Shootings. Journal of the American Society for Information Science and Technology, 63(1), 3447.

Palen, L. \& Vieweg, S., 2008, The emergence of online widescale interaction in unexpected events. In proceedings of the ACM 2008 conference on Computer supported cooperative work - CSCW '08. the ACM 2008 conference. San Diego, CA, USA, (p. 117). Date of access: 21/03/2016. http://portal.acm.org/citation.cfm?doid=1460563.1460583.

Shaw, F., Burgess, J., Craford. K., and Bruns, A., 2013. Sharing news, making sense, saying thanks: Patterns of talk on Twitter during the Queensland floods. Australian Journal of Communication, 40(1), pp. 23-40.

Stallings, R.A., and Quarantelli, E.L., 1985. Emergent citizen groups and emergency management. Public Administration Review, 45, 93-100.

Tapia, A. H., Lalone, N. and Kim, H.W., 2014. Run Amok: Group Crowd Participation in Identifying the Bomb and Bomber from the Boston Marathon Bombing. Proceedings of the 11th ISCRAM.

Wachtendorf, T., and Kendra, J., 2005. Improvising disaster in the city of jazz: Organizational response to Hurricane Katrina. Date of access: 21/03/2016. http://understandingkatrina.ssrc.org/

Weick, K.E., 1993. The collapse of sensemaking in organizations: The Mann Gulch disaster. Administrative Science Quarterly, 38(4), 628-652. 